1 Research Center for Health Policy and Economics, Hitotsubashi University, Tokyo, Japan

2 Tilburg Center for Moral Philosophy, Epistemology and Philosophy of Science (TiLPS), Tilburg University, Tilburg, Netherlands

3 Nuffield Department of Primary Care Health Sciences, University of Oxford, Oxford, UK

Correspondence to: T Rouyard thomas.rouyard@r.hit-u.ac.jp Cite this as: BMJ 2022;376:e064225 http://dx.doi.org/10.1136/bmj-2021-064225 Published: 4 January 2022

\title{
Boosting healthier choices
}

Thomas Rouyard and colleagues discuss use of the boosting approach as an alternative to nudging in developing non-coercive interventions to promote health

\author{
Thomas Rouyard, ${ }^{1}$ Bart Engelen, ${ }^{2}$ Andrew Papanikitas, ${ }^{3}$ Ryota Nakamura ${ }^{1}$
}

The idea of using nudges to change behaviour, introduced by Thaler and Sunstein in $2008,{ }^{1}$ sparked great enthusiasm in policy making communities, including those promoting public health. ${ }^{2}$ Nudges are interventions designed to steer people towards better choices through subtle changes to their environment, such as making unhealthy food less accessible in cafeterias to promote a healthier diet. They can promote behaviour change without using regulations (such as bans) or financial incentives (such as taxes), making them particularly appealing to policy makers. A decade on, many governments and international organisations have established "nudge units" or have developed such behavioural influencing policies.

Yet, despite generating considerable attention, the effects of nudges on health related behaviours are not always clear. ${ }^{3-5}$ While nudges are quite good at motivating one-off behaviours such as getting vaccinated $^{6}$ or attending a health check, ${ }^{7}$ their effects on more complex, continuing behaviours such as self-management of chronic conditions ${ }^{4}$ remain unclear. In addition, long term studies are still lacking for many nudging techniques, ${ }^{48}$ and new evidence suggests that some nudges may not be as effective as originally thought when implemented outside experimental settings. ${ }^{9}$

Nudges are said to be rooted in libertarian paternalism - a framework conceived to improve people's wellbeing while preserving their freedom of choice. ${ }^{1}$ However, critics have challenged these claims, arguing that nudges can undermine liberty ${ }^{10}$ and autonomy, ${ }^{11}$ generating heated debate around their legitimacy. ${ }^{10-15}$ Alternative approaches to behavioural policy and interventions have been proposed, ${ }^{16}$ some of which avoid these ethical concerns. One such approach potentially well suited to health promotion is called boosting. It was conceptualised by philosopher Till Grüne-Yanoff and psychologist Ralph Hertwig ${ }^{17}$ on the premise that human decision making is at odds with some of the assumptions underpinning the nudging approach.

\section{What are boosts?}

Just like nudges, boosts are interventions aimed at influencing people's decisions without coercing them or changing their economic incentives. However, while nudges do so by subtly changing the choice environment, boosts equip people with skills or tools to make better choices themselves.

Take, for example, people with yearly gym memberships who fail to exercise regularly despite genuinely wanting to do so. ${ }^{18}$ This apparent conflict between inner values and actual choices, which can incur economic and health costs, can be explained by a common tendency to overvalue immediate rewards (such as watching television instead of exercising) compared with future, bigger rewards (such as reaching a healthy weight). While there is still uncertainty around what causes this tendency, similar patterns occur when people want and need to follow diets, take medication, and undergo screening. 19

The boosting approach assumes that, in many cases, people can learn to detect and overcome these cognitive errors, thereby over-ruling seemingly irrational choices. ${ }^{20}$ For example, teaching people temptation bundling strategies can boost their self-control and increase gym attendance. ${ }^{21}$ These strategies consist of simultaneously pairing a behaviour that provides delayed rewards (such as exercise) with a pleasurable indulgence (such as watching television), so the former becomes more instantly gratifying.

Boosts can target people's skills directly, as in the previous example, or target the environments in which people make choices. For instance, using fact boxes $^{22}$ to communicate the benefits and harms of a treatment can lead to better informed treatment choices without requiring people to acquire any new skill. ${ }^{2324}$ Fact boxes simplify the choice environment by providing information in formats better suited to human reasoning, such as natural frequencies ( 5 out of 1000 people experience $X$ ) rather than probabilities (the risk of experiencing $\mathrm{X}$ is $0.5 \%),{ }^{25}$ thereby boosting people's capacity to process complex information (fig 1). 


\section{HPV-vaccination}

for the prevention of cervical precancer

The numbers are for girls and women between 15 and 26 years of age, who have received a total of three doses of Cervarix or Gardasil vaccine and have been observed between 15 and 44 months.

\section{Benefits}

How many had a moderate cell change (CIN2)?

How many had an advanced cell change (CIN3)?

How many had a precancerous stage of adenocarcinoma (AIS)?

\section{Harms}

How many suffered from minor side effects at the injection site (swelling, redness, pain, etc.)?

How many suffered from severe side effects (severe infections, inflammations, and other non-lethal complications)
10,000 patients with a placebo vaccination

164

70

9

6,847
10,000 patients with a HPV-vaccination

2

less than 1

less than 1

Short summary: In case of contact with the respective HP viruses, the HPV vaccine can protect against cell changes and precancerous stages of cervical cancer. Vaccination-related redness, swelling or pain at the injection site are possible, but severe reactions are very rare. Permanent harms and deaths caused by the vaccination are not known.

Sources: Arbyn et al. Cochrane Database Syst Rev 2018;5:CD009069.

Last update: October 2019

https://www.hardingcenter.de/en/fact-boxes

Fig 1 | Fact box communicating the benefits and harms of HPV vaccination ${ }^{26}$

These examples highlight a key difference between boosting and education. By equipping people with simple decision strategies or providing information in a way that improves their decision making capacities, boosts are typically less effort and more effective than teaching universal skills, the focus of traditional education. ${ }^{17} 20$
Boosts targeting decision making specific to a single choice environment (choosing a treatment using a fact box) are considered short term, whereas those targeting skills applicable across various relevant environments (temptation bundling for different motivational deficits) are considered long term (table 1). ${ }^{20}$ 
Table 1 | Examples of long and short term boost interventions related to health

\begin{tabular}{|c|c|c|}
\hline Target skills & Target population & Boost intervention \\
\hline \multicolumn{3}{|l|}{ Long term boosts } \\
\hline \multirow[t]{2}{*}{ Self-control } & People wanting to exercise regularly but failing to do so & $\begin{array}{l}\text { "Temptation bundling"-ie, simultaneously pairing a behaviour } \\
\text { that provides delayed rewards (such as exercise) with a } \\
\text { pleasurable indulgence (such as watching a TV series), so the } \\
\text { former becomes more instantly gratifying } 21\end{array}$ \\
\hline & Smokers wanting to quit & Meditation techniques to help control nicotine cravings 27 \\
\hline Processing complex information & General public & $\begin{array}{l}\text { Teaching intuitive decision strategies based on meal colour } \\
\text { variety to facilitate healthy food choices }{ }^{28}\end{array}$ \\
\hline \multicolumn{3}{|l|}{ Short term boosts } \\
\hline Health literacy & Patients choosing between treatment options & Fact boxes to communicate treatment benefits and harms ${ }^{23.25}$ \\
\hline Accurate diagnosis & Doctors assessing patients with suspected cancer & $\begin{array}{l}\text { Collective intelligence rules: simple decision rules derived from } \\
\text { the pooled judgments of multiple doctors } 29\end{array}$ \\
\hline Accurate perception of risk & $\begin{array}{l}\text { Patients receiving information about risk (such as risk of breast } \\
\text { cancer) }\end{array}$ & $\begin{array}{l}\text { Experience based information formats } 30 \text { : user friendly } \\
\text { simulators allowing people to explore the likelihoods of possible } \\
\text { outcomes associated with particular behaviours (such as risk } \\
\text { of breast cancer associated with drinking alcohol) }\end{array}$ \\
\hline Processing complex information & $\begin{array}{l}\text { People deciding whether they should self-isolate during the } \\
\text { covid-19 pandemic }\end{array}$ & $\begin{array}{l}\text { "Fast-and-frugal" decision trees: simple decision aids that limit } \\
\text { the number of questions or frame choices intuitively and } \\
\text { memorably } 31\end{array}$ \\
\hline
\end{tabular}

\section{How do boosts differ from nudges?}

Both nudges and boosts address seemingly irrational decisions resulting from human reasoning and both build on psychological and behavioural insights. In fact, some interventions, such as putting nutrition labels on the front of packaging-arguably qualify as both nudges and boosts. ${ }^{20}$ However, the two types of intervention typically work in different ways. Unlike boosts, nudges redesign so called choice architecture and create environments that harness people's cognitive or motivational deficiencies to prompt choices in largely non-conscious ways. For example, switching from an opt-in to an opt-out policy for organ donation relies on people's tendency to prefer inaction over action (status quo bias), resulting in higher rates of organ donor registrations. ${ }^{32}$

To illustrate the difference, think of interventions to reduce smoking rates. A nudge could consist of reducing the visibility of tobacco products in stores to mitigate the effect of smokers' "attentional bias" for tobacco related cues. ${ }^{33}$ This strategy is both libertarian (smokers can still buy tobacco) and paternalistic (the environment is modified to prompt them not to buy tobacco). Alternatively, a boost strategy could consist of teaching smokers meditation techniques that increase self-control over nicotine cravings. ${ }^{27}$ Table 2 provides further examples.

Table 2 | Boost and nudge interventions targeting similar health related choices

\begin{tabular}{|c|c|c|}
\hline Choice & Boost intervention & Nudge intervention \\
\hline Exercising & $\begin{array}{l}\text { Temptation bundling strategies to enhance self-control abilities } \\
\text { through the pairing of exercise with a pleasurable indulgence }\end{array}$ & Using motivational signs to prompt stair use \\
\hline Diet & $\begin{array}{l}\text { Intuitive decision strategies based on colour variety in meals } \\
\text { to facilitate healthy food choices }\end{array}$ & $\begin{array}{l}\text { Rearranging food items at cafeterias to make healthy food easier } \\
\text { to choose }\end{array}$ \\
\hline Cancer screening & $\begin{array}{l}\text { Fact boxes to boost processing of complex information and } \\
\text { facilitate decision making }\end{array}$ & Framing risk information to make it more impactful \\
\hline Smoking & $\begin{array}{l}\text { Meditation techniques to enhance self-control over nicotine } \\
\text { cravings }\end{array}$ & $\begin{array}{l}\text { Reducing the visibility of tobacco products in shops to mitigate } \\
\text { smokers' attentional bias }\end{array}$ \\
\hline
\end{tabular}

The differences in design between nudges and boosts reflect differing interpretation of people's decision making processes. ${ }^{17}$ Proponents of boosts think that people's poor choices result from a misuse of their inner decision making toolbox-for example, because of confusing information-and assume that people can often learn new skills or use adapted tools enabling them to overcome these problems. Conversely, for proponents of nudges, poor choices result from cognitive deficiencies that occur systematically because of the way human cognition works. People will never be free from these deficiencies, but nudges can be designed to harness them to promote better outcomes. ${ }^{17}$

\section{Why do conceptual differences matter?}

Conceptual differences between boosts and nudges matter because they have different ethical implications. Nudges do not require people to be aware of the intervention, which can raise concerns about autonomy and consent. Boosts, by contrast, require a minimum of motivation and cooperation.

Consider, for example, a health professional who wants to motivate a patient to exercise by communicating their risk of a heart attack. A boost might provide brief statistical literacy training to enhance the patient's understanding of probability, so that they can make better informed lifestyle choices. ${ }^{34}$ A nudge, however, might present risk information in a way that is more likely to trigger behaviour change automatically (eg, using relative not absolute risks ${ }^{35}$ or 
emotionally charged images ${ }^{36}$ ). While the nudge uses unconscious factors to influence choices, arguably threatening the patient's autonomy, ${ }^{11}$ the boost requires their active participation, thereby avoiding such a charge.

Another problem is the criteria used to decide in which direction people should be nudged. Nudge originators, Thaler and Sunstein, argue that "it is legitimate for choice architects to try to influence people's behaviour in order to make their lives longer, healthier and better." Importantly, they indicate that the ultimate objective is to "make choosers better off, as judged by themselves." ${ }^{1}$ Without this criterion, behaviour would be steered towards what nudgers think best, making nudges no different from classic paternalistic interventions. ${ }^{10} 37$

However, meeting this criterion assumes that nudgers can identify people's life goals and design nudges accordingly. This is arguable. Preferences can vary across time and contexts. They can also vary across people, implying that one-size-fits-all nudges cannot realistically benefit everyone. ${ }^{1037}$ Even when a nudger is genuinely benevolent their idea of benefit might differ from that of the nudge recipient. And nudgers aren't always benevolent, even in healthcare-for example, clinicians nudging patients towards treatments in which they have a vested interest.

Boosts, on the other hand, are relatively immune to such concerns. They are designed to help people make better choices themselves. Boost recipients are free to use their acquired new skills or not. Knowledge of their life goals is not required, and differences in life goals within and between individuals are irrelevant.

Nevertheless, boosts also have limitations, particularly for people without the cognitive resources or motivation to learn and use new skills. For example, boosts may primarily benefit health conscious individuals who are willing and able to invest time and effort in boosting a skill. These individuals may already have healthier habits and higher socioeconomic status. Boosts may therefore worsen (socioeconomic) inequalities in health. The fact that boosts promote agency and maintain autonomy in ways that nudges often do not, has the downside of making boosts more demanding and potentially less effective or equitable.

\section{Boost, nudge, or both?}

Empirical evidence on the relative benefits and harms of boosting remains limited. The seminal paper was published only five years ago, ${ }^{17}$ although some earlier interventions have since been classified as boosts. ${ }^{232738}$ While various boosts have been shown to promote health related outcomes, ${ }^{21} 232728$ effects may vary over time and across target populations and behaviours. ${ }^{24} 2529$ What matters in the end is which interventions achieve enduring changes in behaviour without violating widely held values such as autonomy and agency.

Importantly, boosting shows promise in protecting people from the detrimental effects of "unhealthy" nudges already present in the environment (from fast food or gambling industries, for example). Assuming that the boosted skills effectively overcome cognitive biases, people may become less prone to malign nudges that rely on such biases. ${ }^{39}$ However, by neutralising the biases that make people susceptible to nudges, boosts may reduce the opportunity for effective nudge policies should they be required (nudging always leaves open the option for boosting, but not vice versa). 39

The key challenge, then, is to determine the situations best suited to boosting or nudging. Nuanced policy making should not consider either of these behavioural policy tools a silver bullet, or systematically prefer one over the other. More research is required to explore benefits of both types of intervention in different settings and populations, and also in the long term. In the meantime, boosts should be considered a useful additional tool for both health policy makers and clinicians.

\section{Key messages}

- The legitimacy of some health promoting nudges is subject to debate and their effectiveness is not always clear

- Another approach to behavioural policy has recently been proposed, known as boosting

- Boost interventions provide people with skills or tools to make better choices themselves

- Unlike nudges, boosts do not threaten autonomy or agency but may reduce equity

- Boosts should be considered when designing non-financial, non-regulatory behavioural interventions

Contributors and sources: Each author has contributed a specific expert point of view to this paper. TR studies new approaches to inform the development of behavioural policies aimed at improving population health. BE is a moral and political philosopher with extensive research experience on the ethics of nudging. AP is a general medical practitioner with professional and academic interests in medical ethics education. RN is a health economist and policy expert conducting behavioural health research to inform public health policies. TR wrote the initial draft of the paper and all authors equally contributed to revising it.

Competing interests: We have read and understood BMJ policy on declaration of interests and have no relevant interests to declare.

Provenance and peer review: Not commissioned; externally peer reviewed.

TR is supported by the Japan Society for the Promotion of Science (KAKENHI grant-in-aid for early-caree scientists-grant No 20K18934). RN is supported by the Ministry of Health, Labour and Welfare of Japan (Health and Labour Sciences Research Grant-grant No 20FA1022).

Thaler RH, Sunstein C. Nudge: improving decisions about health, wealth, and happiness. Yale University Press, 2008

Marteau TM, Ogilvie D, Roland M, Suhrcke M, Kelly MP. Judging nudging: can nudging improve population health?BM/2011;342:d228. doi: 10.1136/bmj.d228 pmid: 21266441

Hummel D, Maedche A. How effective is nudging? A quantitative review on the effect sizes and limits of empirical nudging studies. J Behav Exp Econ 2019;80:47-58. doi: 10.1016/j.socec.2019.03.005

4 Möllenkamp M, Zeppernick M, Schreyögg J. The effectiveness of nudges in improving the self-management of patients with chronic diseases: A systematic literature review. Health Policy 2019;123:1199-209. doi: 10.1016/j.healthpol.2019.09.008 pmid: 31676042

Bucher T, Collins C, Rollo ME, etal. Nudging consumers towards healthier choices: a systematic review of positional influences on food choice. Br J Nutr 2016;115:2252-63. doi: 10.1017/S0007114516001653 pmid: 27185414

6 Chapman GB, Li M, Colby H, Yoon H. Opting in vs opting out of influenza vaccination. JAMA 2010;304:43-4. doi: 10.1001/jama.2010.892 pmid: 20606147

Altmann S, Traxler C. Nudges at the dentist. Eur Econ Rev 2014;72:19-38.doi: 10.1016/j.euroecorev.2014.07.007.

8 Sanders M, Snijders V, Hallsworth M. Behavioural science and policy: where are we now and where are we going?Behav Public Policy 2018;2:144-67. doi: 10.1017/bpp.2018.17

9 DellaVigna S, Linos E. Rcts to scale: comprehensive evidence from two nudge units. No w27594. National Bureau of Economic Research, 2020.doi: 10.3386/w27594.

10 Grüne-Yanoff T. Old wine in new casks: libertarian paternalism still violates liberal principles. Soc Choice Welfare 2012;38:635-45.doi: 10.1007/s00355-011-0636-0.

11 Hausman DM, Welch B. Debate: to nudge or not to nudge. J Polit Philos 2010;18:123-36. doi: 10.1111/j.1467-9760.2009.00351.x

12 Quigley M. Nudging for health: on public policy and designing choice architecture. Med Law Rev 2013;21:588-621. doi: 10.1093/medlaw/fwt022 pmid: 24081425

13 Sunstein CR. Fifty shades of manipulation. J Mark Behav 2015;1:213-44.

14 Sugden R. The community of advantage: a behavioural economist's defence of the market. Oxford University Press, 2018.doi: 10.1093/oso/9780198825142.001.0001.

15 Engelen B. Ethical criteria for health-promoting nudges: a case-by-case analysis. Am J Bioeth 2019:19:48-59. doi: 10.1080/15265161.2019.1588411 pmid: 31068115

16 Oliver A. Nudging, shoving, and budging: behavioural economic-informed policy. Public Adm 2015;93:700-14. doi: 10.1111/padm.12165

17 Grüne-Yanoff T, Hertwig R. Nudge versus boost: how coherent are policy and theory?Minds Mach 2016:(1-2):149-83. doi: 10.1007/s11023-015-9367-9. 
18 DellaVigna S, Malmendier U. Paying not to go to the gym. Am Econ Rev 2006;96:694-719.doi: 10.1257/aer.96.3.694.

19 Wang Y, Sloan FA. Present bias and health. J Risk Uncertain 2018;57:177-98. doi: 10.1007/s11166-018-9289-z pmid: 31244508

20 Hertwig R, Grüne-Yanoff T. Nudging and boosting: steering or empowering good decisions. Perspect Psychol Sci 2017 ; 12 :973-86. doi: doi :10.1177/1745691617702496 pmid: 28792862

21 Kirgios EL, Mandel GH, Park Y, etal. Teaching temptation bundling to boost exercise: a field experiment. Organ Behav Hum Decis Process 2020;161(Suppl):20-35. doi: 10.1016/j.obhdp.2020.09.003

22 Gigerenzer G, Kolpatzik K. How new fact boxes are explaining medical risk to millions. BMJ 2017;357:j2460. doi: 10.1136/bmj.j2460 pmid: 28539314

23 Schwartz LM, Woloshin S, Welch HG. Using a drug facts box to communicate drug benefits and harms: two randomized trials. Ann Intern Med 2009:150:516-27. doi: 10.7326/0003-4819-150-8-200904210-00106 pmid: 19221371

24 McDowell M, Gigerenzer G, Wegwarth O, Rebitschek FG. Effect of tabular and icon fact box formats on comprehension of benefits and harms of prostate cancer screening: a randomized trial. Med Decis Making 2019;39:41-56. doi: 10.1177/0272989X18818166 pmid: 30799691

25 Eber MR, Sunstein CR, Hammitt JK, Yeh JM. The modest effects of fact boxes on cancer screening. J Risk Uncertain 2021;62:29-54. doi: 10.1007/s11166-021-09344-x pmid: 34385760

26 Harding Center for Risk Literacy. HPV vaccination for the prevention of cervical precancer. https://www.hardingcenter.de/en/projects-and-collaborations/fact-boxes/vaccines/hpv-vaccinationprevention-cervical-precancer

27 Tang YY, Tang R, Posner MI. Brief meditation training induces smoking reduction. Proc Natl Acad Sci U S A 2013;110:13971-5. doi: 10.1073/pnas.1311887110 pmid: 23918376

28 König LM, Renner B. Boosting healthy food choices by meal colour variety: results from two experiments and ajust-in-time ecological momentary intervention. BMC Public Health 2019;19:975. doi: 10.1186/s12889-019-7306-z pmid: 31331299

29 Kurvers RH, Herzog SM, Hertwig R, etal. Boosting medical diagnostics by pooling independent judgments. Proc Natl Acad Sci U S A 2016:113:8777-82. doi: 10.1073/pnas.1601827113 pmid: 27432950

30 Hogarth RM, Soyer E. Providing information for decision making: contrasting description and simulation. J Appl Res Mem Cogn 2015 ; 4 :221-8.doi: doi :10.1016/j.jarmac.2014.01.005.

31 Lunn PD, Timmons S, Julienne $\mathrm{H}$, etal. Using decision aids to support self-isolation during the COVID-19 pandemic. Psychol Health 2021;36:195-213.pmid: 33210950

32 Johnson EJ, Goldstein D. Medicine. Do defaults save lives? Science 2003;302:1338-9. doi: 10.1126/science.1091721 pmid: 14631022

33 Ford A, MacKintosh AM, Moodie C, Kuipers MAG, Hastings GB, Bauld L. Impact of a ban on the open display of tobacco products in retail outlets on never smoking youth in the UK: findings from a repeat cross-sectional survey before, during and after implementation. Tob Control 2020;29:282-8.pmid: 31088915

34 Gigerenzer G, Hoffrage U. How to improve Bayesian reasoning without instruction: frequency formats. Psychol Rev 1995;102:684. doi: 10.1037/0033-295X.102.4.684.

35 Sarfati D, Howden-Chapman P. Woodward A, Salmond C. Does the frame affect the picture? A study into how attitudes to screening for cancer are affected by the way benefits are expressed. J Med Screen 1998;5:137-40. doi: 10.1136/jms.5.3.137 pmid: 9795874

36 Näslund U, Ng N, Lundgren A, etalVIPVIZA trial group. Visualization of asymptomatic atherosclerotic disease for optimum cardiovascular prevention (VIPVIZA): a pragmatic, open-label, randomised controlled trial. Lancet 2019;393:133-42. doi: 10.1016/S0140-6736(18)32818-6 pmid: 30522919

37 Sugden R. Do people really want to be nudged towards healthy lifestyles? Int Rev Econ 2017;64:113-23.doi: 10.1007/s12232-016-0264-1.

38 Sedlmeier P, Gigerenzer G. Teaching Bayesian reasoning in less than two hours. J Exp Psychol Gen 2001;130:380-400. doi: 10.1037/0096-3445.130.3.380 pmid: 11561916

39 Hertwig R, Ryall MD. Nudge versus boost: agency dynamics under libertarian paternalism. Econ J (Lond) 2020;130:1384-415.doi: 10.1093/ej/uez054.

This is an Open Access article distributed in accordance with the Creative Commons Attribution Non Commercial (CC BY-NC 4.0) license, which permits others to distribute, remix, adapt, build upon this work non-commercially, and license their derivative works on different terms, provided the original work is properly cited and the use is non-commercial. See: http://creativecommons.org/licenses/by$\mathrm{nc} / 4.0 \%$ 